\title{
Strategic decision concerning tourist origins portfolio: A decision process based on the ELECTRE method and applied to French Polynesia
}

\author{
Laurent Botti ${ }^{1 *}$, Linjia Zhang ${ }^{2}$ and Sylvain Petit ${ }^{3}$
}

1. Université de Perpignan Via Domitia, IAE, CRESEM

2. International Business School Suzhou, Xi'an Jiaotong - Liverpool University, China.

3. Université de la Polynesie Française, CETOP-GDI; Université Polytechnique des Hauts de France, IDP.

\section{* Corresponding author: laurent.botti@univ-perp.fr}

\begin{abstract}
This paper presents a two-step framework for the selection of the optimal tourist origins portfolio for a particular destination. The paper applies this decision-making process to French Polynesia. The first step of the framework is based on a mean-variance optimization procedure and proposes the subset of portfolios among which the decision-maker must limit her-his choice. Second, the multi-criteria ELECTRE method is employed to rank all the portfolios considered on the basis of decision-makers' preferences exposed in the parameters of the algorithm. Three decision-maker profiles are proposed from a risk-averse profile to a risk-lover profile. This paper contributes to the dedicated literature by presenting ELECTRE III as an alternative to the utility function approach used by previous studies. Results of our application to French Polynesia's tourist attendance data (from 2014 to 2017) highlight the usefulness of the framework exhibited and empirically underline the economic perspectives offered by Chinese tourists. The French Polynesian application follows a clear presentation permitting consideration of applications to other destinations.
\end{abstract}

Keywords: Performance, Multi Criteria Decision Making (MCDM), ELECTRE, MeanVariance approach 


\section{Introduction}

As competition among destinations intensifies, the adoption of appropriate strategies is an obligation for destination management organizations (DMOs - Sainaghi, 2006) to gain a competitive advantage for their destination and develop the economy of their territory, especially by orienting marketing choices towards inbound markets. As a consequence, destination managers attempt to determine the best market mix for their destination, which is the optimal number of overnight stays by tourists according to their origin. The present study addresses this issue and proposes a decision-making model for evaluating tourist origins portfolio for a particular destination. The decision-making model provides a solution to the decision-maker that is the DMO of the destination to seek the satisfactory solution for solving the diversification of tourist origins. Consequently, this paper builds on the strategy content literature concerning destination management by suggesting a model to formulate a diagnosis for destination attendance and the optimal strategy to improve it.

Since the works of Kennedy (1998), the number of overnight stays from different tourist origins is considered in the dedicated literature to represent a risky asset. Tourist origins portfolio management is currently a topic of interest among academics (Jang, 2004; Jang and Chen, 2008; Botti et al., 2012; Ratsimbanierana et al., 2013; Zhang et al., 2016; Rakotondramaro and Botti, 2018). Among those studies, just two discuss the decision between efficient portfolios. Zhang et al. (2016) and Rakotondramaro and Botti (2018) propose a framework to analyze the real origins portfolios of a destination and to recommend to the decision-maker (the DMO) an optimum choice in terms of attendance. Our paper follows this literature and proposes to improve the existing methodology by filling in the gap concerning the choice of the satisfactory portfolio among all efficient ones.

For that purpose, the present paper proposes a two-step methodology comprising the meanvariance (M-V) approach and the Multi-Criteria Decision Making (MCDM) ELECTRE method (Elimination et Choix Traduisant la Réalité - Roy, 1991). The M-V approach identifies two non-compensatory criteria on which efficient portfolios are analyzed. Our methodology then applies the ELECTRE algorithm to rank these portfolios by considering the decision-maker risk profile. As a consequence, the first portfolio in the ranking must be understood as the satisfactory one. The methodological contribution of this paper stands in the presentation of the ELECTRE method as an alternative to the utility function approach previously used in the literature by Zhang et al. (2016) and Rakotondramaro and Botti (2018).

This paper uses a case study to prove the interests of our two-step framework. We apply our methodology on the particular case of French Polynesia. This destination is remote and hosts not more than 200000 tourists per year. The diversification of tourist origins is quite low as French and American tourists represent nearly $60 \%$ of arrivals. Other tourist origins are Japan, Australia, New Zealand and other European countries (Spain, Italy, UK, Switzerland and Germany). Chinese tourists are still a marginal phenomenon, but our approach suggests the economic importance of this origin to the local DMO.

Section 2 develops the idea that ELECTRE is useful in helping the decision-maker in his or her decisions concerning the tourist origins portfolio of his or her destination. Thus, this section will review the previous literature on the topic and will establish the foundations of our framework. Section 3 introduces the French Polynesia case study and describes the process of the empirical study. This section reports results, discusses findings and exposes the managerial implications of our framework. Section 4 presents the conclusion and limitations 
of the paper, and raises possible extensions of the strategic decision-making framework for future research. The extension concerns not only tourist attendance optimization of destinations, but also the application of MCDM methods in the tourism context.

\section{Choosing a satisfactory portfolio with ELECTRE III}

The present paper proposes a methodology comprising the M-V approach and the MCDM ELECTRE method. The methodology aims to help DMOs make decisions about the efficiency of their marketing resources. In today's competitive tourism economy, DMOs face a growing pressure to reduce their costs while at the same time improve the return on their investments. Accordingly, there is a common goal for DMOs to increase the efficiency of their choices. Authors such as Assaf (2012), Goncalves (2013), Assaf and Tsionas (2018) and Chang et al. (2017) have designed efficiency measurements of tourism sectors. Concerning destinations, the works of Barros et al. (2011), Assaf and Josiassen (2012), Assaf and Tsionas (2015) and Corne (2015) must be cited. However, except Zhang et al. (2016), very few works have proposed to improve the decision-making process of DMOs by considering the attendance of their destination. Nevertheless, considering the development level of tourism industries around the world, the question is more about optimizing tourist attendance than attracting tourists, especially in the case of islands with limited tourism facilities like hotels. Accordingly, our method is applied to a case that corresponds to this contextual setting, namely French Polynesia.

Until the present day, the relevant literature has used the modern portfolio theory (MPT) developed by Markowitz (1952) to address this issue. MPT supposes that investors make their asset selection decision with two criteria: return and risk. Return is usually measured by mean, and variance is used as a risk criterion. In the $\mathrm{M}-\mathrm{V}$ approach, the portfolio selection process breaks down into two parts. First, after estimating the return and the risk of each portfolio (composed of different weights of each possible asset), the decision-maker can choose efficient ones. Then, among efficient portfolios, the manager must select one portfolio as a benchmark for his or her ensuing strategies. This portfolio selection is one of the choice problematics when considering decisional theory (Figueira et al., 2005).

In previous papers on this theme, Zhang et al. (2016) and Rakotondramaro and Botti (2018) use the utility function technique to fill in this research gap. However, this technique relies on a utility value, which is a function of an investor's risk aversion index written A. In the financial literature, this index takes values from 2.0 to 4.0 (Bodie et al., 2009). In their studies, Zhang et al. (2016) and Rakotondramaro (2018) used different values for that investor's risk aversion index. In the literature under discussion, and as far as we are concerned, nothing is mentioned about how managers should proceed to fix that index. It is explained, however, that $\mathrm{A}=3$ is used to represent the average risk aversion, that $\mathrm{A}>3$ means more risk aversion and that $\mathrm{A}<3$ means less risk aversion. In our paper, we propose to use risk profiles that integrate the parameters of the ELECTRE method. As a consequence, our approach contributes in an original and useful way to the decision-making process concerning tourist origins portfolio for a destination. Decision-maker preferences are revealed by her-his risk profile (evaluation of her-his individual willingness to take risks) rather than by a risk/return trade-off. In addition, the decision-maker could avoid a trade-off between these two criteria as non-compensatory methods as ELECTRE allow to do so.

ELECTRE is part of the MCDM methods which concern quantitative approaches that allow the aggregation of several evaluation criteria to decide between a set of alternatives. These 
methods are classified into two groups: compensatory and non-compensatory. The noncompensatory ELECTRE method is based on outranking relations which are binary relations defined on a set of alternatives to the decision. ELECTRE originated in Europe in the mid1960s and has evolved into several extensions (Zopounidis, 1999, Hatami-Marbini \& Tavana, 2011). The literature concerning the ELECTRE methods in the tourism field is quite narrow (Andrades-Caldito et al., 2013; Ishizaka et al., 2013; Botti \& Peypoch, 2013). Concerning our problem, that is, how to choose between various efficient tourist origins portfolios, ELECTRE is relevant for at least two reasons (among the different reasons exposed by Figueira et al., 2005): (i) the problem does not tolerate a compensation effect between return and risk, and (ii) there is a need to use thresholds, as indifference thresholds, such that small differences may be insignificant. In this paper, we propose to use ELECTRE III (Almeida Dias et al., 2006) as a method to rank efficient portfolios determined by the first step of our framework.

The ELECTRE method comprises two parts: (i) construction of outranking relations based on the combination of a concordance index and a discordance index between two alternatives, and (ii) exploitation of these relations to construct recommendations concerning alternatives to the decision. The nature of the recommendations depends on the decision problem since the aim of MCDM methods is to provide tools to the decision-maker that allow a decision problem to be solved: by choosing, sorting or ranking alternatives. ELECTRE III answers ranking decision problems. ELECTRE III is a well-known method (it has been widely used as revealed by Giannoulis and Ishizaka, 2010) but it has never been employed in the tourist origins portfolio context.

The construction of an outranking relation is based on two major concepts: (i) concordance: An outranking relation is validated if a sufficient majority of criteria are consistent with it. (ii) Non-discordance: When the concordance condition holds, none of the criteria that are inconsistent with it should oppose too strongly (by considering the veto threshold). These two conditions (formally set out in the technical annex) must be fulfilled to validate an outranking relation. Outranking relations are not necessarily transitive because of the Condorcet effect and incomparability (Hatami-Marbini and Tavana, 2011). Considering the concordance and discordance indices, the degree of credibility indicates if the outranking relation is supported by the reality provided by the performance matrix. From the credibility matrix, a procedure named distillation must be used to rank the alternatives in two pre-orders (the first is obtained with a descending distillation, the second with an ascending distillation) which are combined in the final ranking. For a detailed presentation of the ELECTRE III method see Rogers, 2000; Papadopoulos and Karagiannidis, 2008; and Giannoulis and Ishizaka, 2010.

As exposed in the ELECTRE algorithm, the decision-maker needs to evaluate and decide on $n$ alternatives represented by the vector $\mathrm{A}$ : $(\mathrm{Ai} ; \mathrm{i}=1,2, \ldots, \mathrm{n})$, which could be analyzed by $\mathrm{m}$ criteria represented by the vector $\mathrm{C}$ : $(\mathrm{Cj} ; \mathrm{j}=1,2, \ldots, \mathrm{m})$. The weight of criteria varies from one decision-maker to another and is represented by the vector $\mathrm{W}:(\mathrm{Wj} ; \mathrm{j}=1,2, \ldots, \mathrm{m})$. The assessment of each alternative $i$ on each criterion $j$ gives the performance matrix composed of all the Rij, presented in the Table 1 . 
Table 1: Performance matrix

\begin{tabular}{|c|c|c|c|c|}
\cline { 2 - 5 } \multicolumn{1}{c|}{} & \multicolumn{4}{c|}{ Decision-making criterion (Cj) } \\
\cline { 2 - 5 } & & $\mathrm{C}_{1}$ & $\ldots$ & $\mathrm{C}_{\mathrm{m}}$ \\
\hline \multirow{3}{*}{$\begin{array}{c}\text { Alternatives to the } \\
\text { decision (Ai) }\end{array}$} & $\mathrm{A}_{1}$ & $\mathrm{R}_{11}$ & $\cdots$ & $\mathrm{R}_{1 \mathrm{~m}}$ \\
\cline { 2 - 5 } & $\ldots$ & $\ldots$ & $\ldots$ & $\cdots$ \\
\cline { 2 - 5 } & $\mathrm{A}_{\mathrm{n}}$ & $\mathrm{R}_{\mathrm{n} 1}$ & $\cdots$ & $\mathrm{R}_{\mathrm{nm}}$ \\
\hline $\begin{array}{c}\text { Weights of criteria } \\
(\mathbf{W j})\end{array}$ & & $\mathrm{W}_{1}$ & $\cdots$ & $\mathrm{W}_{\mathrm{m}}$ \\
\hline
\end{tabular}

ELECTRE III uses a fuzzy framework to take into account human reasoning. Thus, criteria composing the vector $\mathrm{C}$ are pseudo-criteria with indifference and preference thresholds, as presented in the Figure 1. In this figure, Diff stands for the difference between the performance of two alternatives (here the alternative a and the alternative b) on a particular criterion. This aspect is cardinal in the ELECTRE method since the reasoning is done within the criteria (between a pair of alternatives) and not between criteria as in compensatory methods (which use tradeoffs between criteria). Note that in Figure 1, the decision-maker chooses to give importance to big values because he or she will prefer alternative a to alternative $b$ if Diff is $>q_{j}$ which is the indifference thresholds for criterion $j$. 
Figure 1 : ELECTRE III algorithm

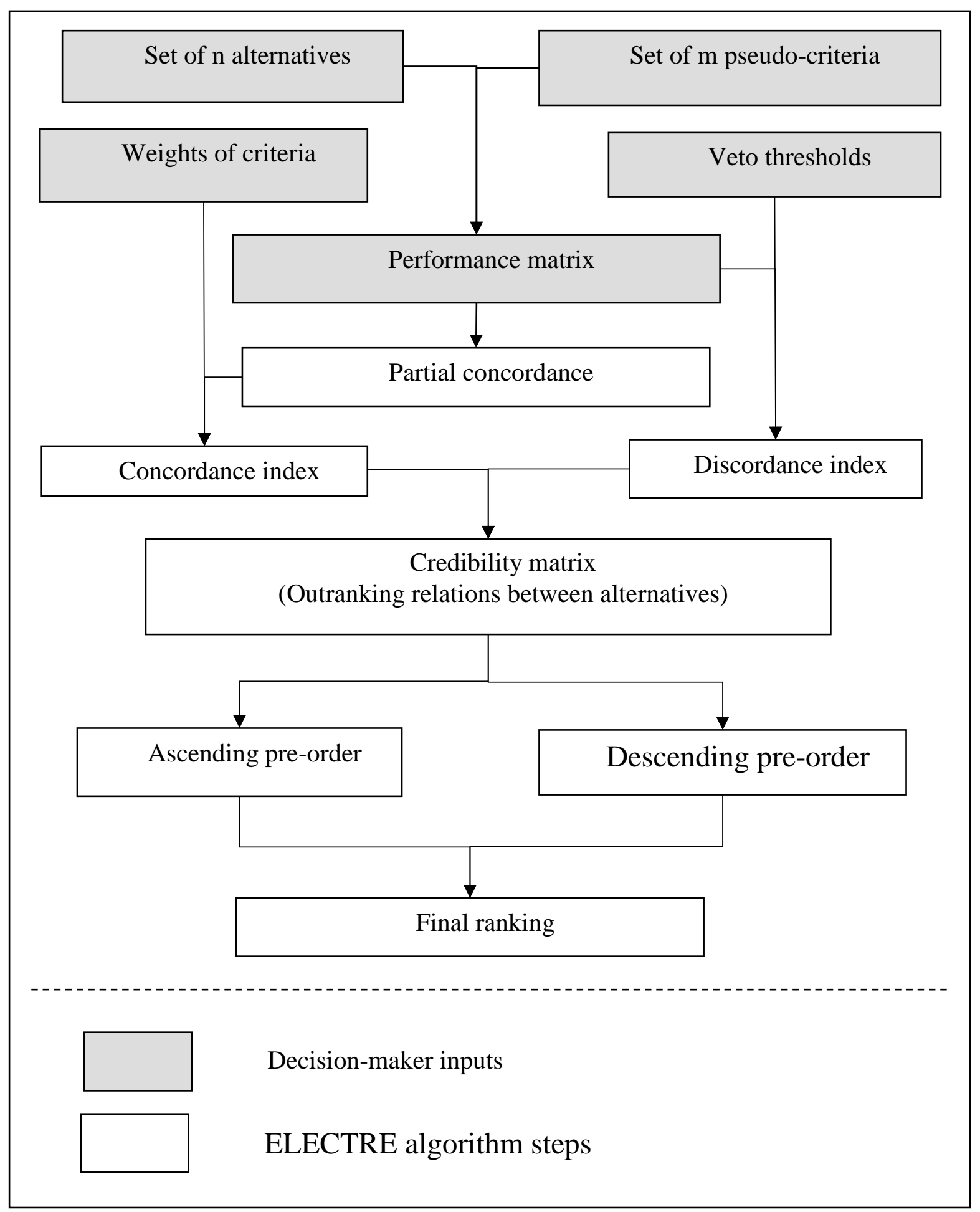


Figure 2: Pseudo criterion (maximum as a sense of preference)

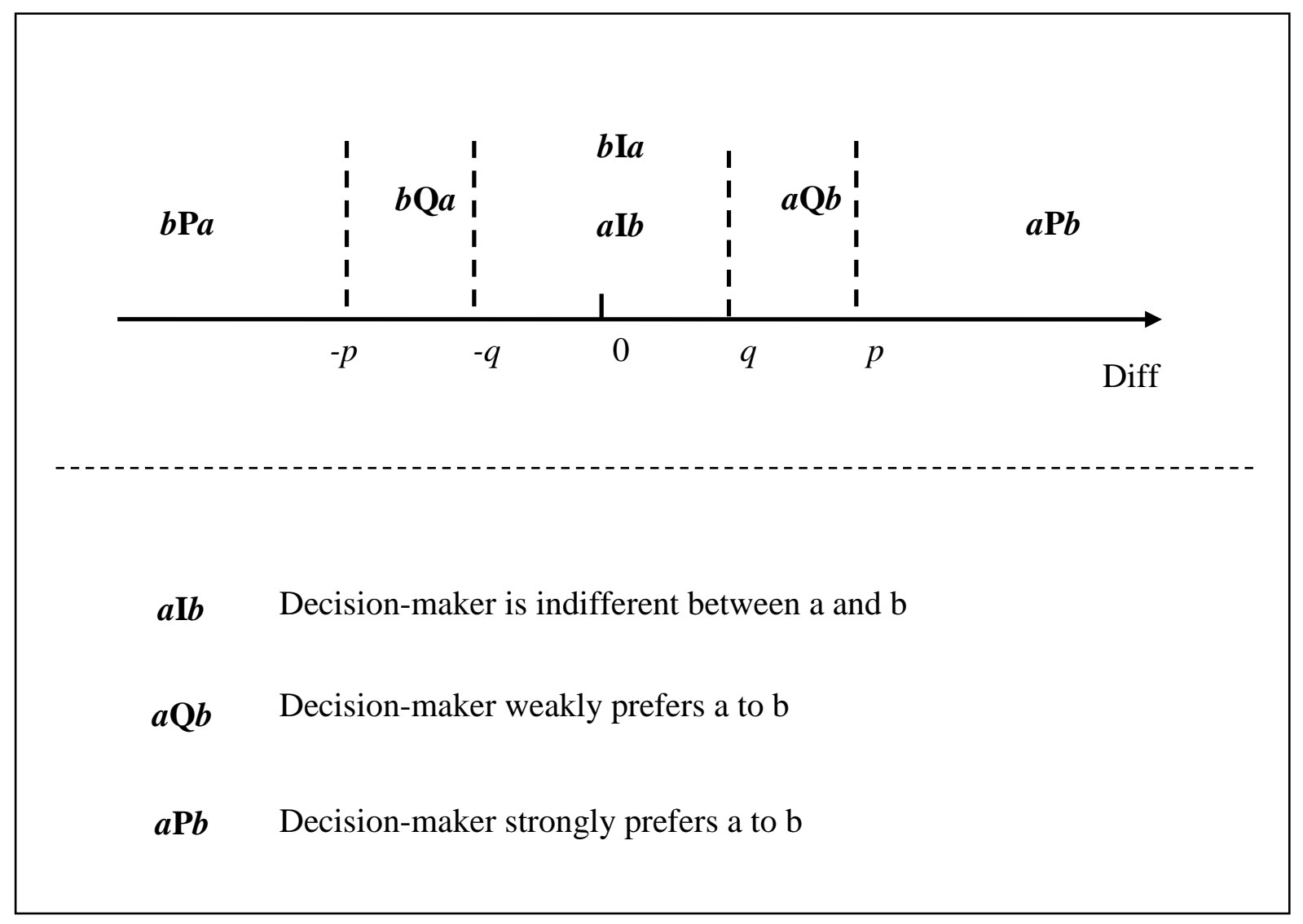

\section{Empirical study: The French Polynesia case}

Islands are unique tourism experiences but may have disadvantages compared with mainland destinations (Seraphin et al., 2016). Tourism demand (which is inherently unstable as exposed by Sinclair, 1999) affects the local economy, and managerial decisions concerning it should accordingly be made methodologically to be considered relevant. This is particularly so in the case of islands that exclusively depend on tourism for their economy (Stauvermann and Kumar, 2016), like French Polynesia. Tourism is the most important economic activity for French Polynesia, but the number of tourist arrivals is only approximately 200000 tourists (so less than 1 tourist per inhabitant). The accommodation capacity is extremely limited (about 4 200 rooms including 2700 rooms in the hotel sector) but characterized by a relatively high occupancy rate (close to $80 \%$ during the high season) and an important average on the length of stay (more than 2 weeks). As a consequence, decisions concerning the optimization of tourism demand should be made. Poirine (2011) and Dropsy et al. (2018) demonstrated that tourism arrivals in French Polynesia are quantitatively insufficient. As it was pointed out by Petit (2018), the marketing strategy used to attract tourists at the beginning of the 2000s was not adapted to the international tourism competition at that time. As we can easily identify market sources of this remote destination, we should propose a strategy for the local tourism authority in terms of optimal tourist origins portfolio.

Following the literature (Botti, et al., 2012; Zhang et al., 2015; Rakotondramaro and Botti, 2018), we use the number of overnight stays from different tourist origins as risky assets constituting the portfolio of the destination. Table 2 presents origins and their respective 
weights in each annual portfolio. Data are derived from the monthly statistical survey of the number of overnight stays by origins of tourists (Africa, Central America, North America, South America, China, Japan, Europe, France, Pacific, Middle East) realized by the local office of statistics (ISPF, Institut de Statistiques de la Polynésie Française) and cover the period from 2014 to 2017.

Table 2: Origins and their respective weights in the French Polynesia porfolio

\begin{tabular}{|c|c|c|c|c|}
\hline & 2014 & 2015 & 2016 & 2017 \\
\hline Africa & $0.23 \%$ & $0.18 \%$ & $0.20 \%$ & $0.21 \%$ \\
\hline Central America & $0.45 \%$ & $0.44 \%$ & $0.38 \%$ & $0.38 \%$ \\
\hline North America & $28.38 \%$ & $28.86 \%$ & $29.46 \%$ & $28.77 \%$ \\
\hline South America & $3.11 \%$ & $3.23 \%$ & $3.99 \%$ & $3.72 \%$ \\
\hline China & $1.64 \%$ & $2.93 \%$ & $2.92 \%$ & $2.63 \%$ \\
\hline Japan & $5.20 \%$ & $5.21 \%$ & $5.10 \%$ & $4.81 \%$ \\
\hline Europe & $18.32 \%$ & $17.72 \%$ & $15.74 \%$ & $15.34 \%$ \\
\hline France & $32.63 \%$ & $31.52 \%$ & $32.79 \%$ & $33.69 \%$ \\
\hline Total Pacific & $9.83 \%$ & $9.73 \%$ & $9.12 \%$ & $10.16 \%$ \\
\hline Middle East & $0.21 \%$ & $0.18 \%$ & $0.30 \%$ & $0.28 \%$ \\
\hline
\end{tabular}

Using Matlab, four efficient frontiers for four real portfolios of tourist origins (from 2014 to 2017) have been constructed by using the multi-constraint optimization model presented in previous papers such as Zhang et al. (2016) and Rakotondramaro and Botti (2018). Figure 2 exposes the four real portfolios and their respective efficient frontiers. The shape of the frontiers confirms the positive correlation between risk and return at the basis of the MPT. The four real portfolios are sub-optimal, highlighting the interest of our methodology. Each optimal portfolio $(2014,2015,2016$ and 2017) is represented by a sign, as well as its efficiency frontier.

To determine the efficient frontiers, we generated a set of optimized portfolios by considering a lower limit to each tourist origins weight. For a particular origin, the lower boundary (LB) is a part of the market share. In the previous literature, Rakotondramaro and Botti (2018) represented the only study in which an LB is used. This boundary maintains an LB for each origin in the portfolio and corresponds in our paper to $80 \%$ of the lowest weight of the concerned origin in real portfolios from 2014 to 2017. 
Figure 3: Efficient porfolios for French Polynesia 2014-2017

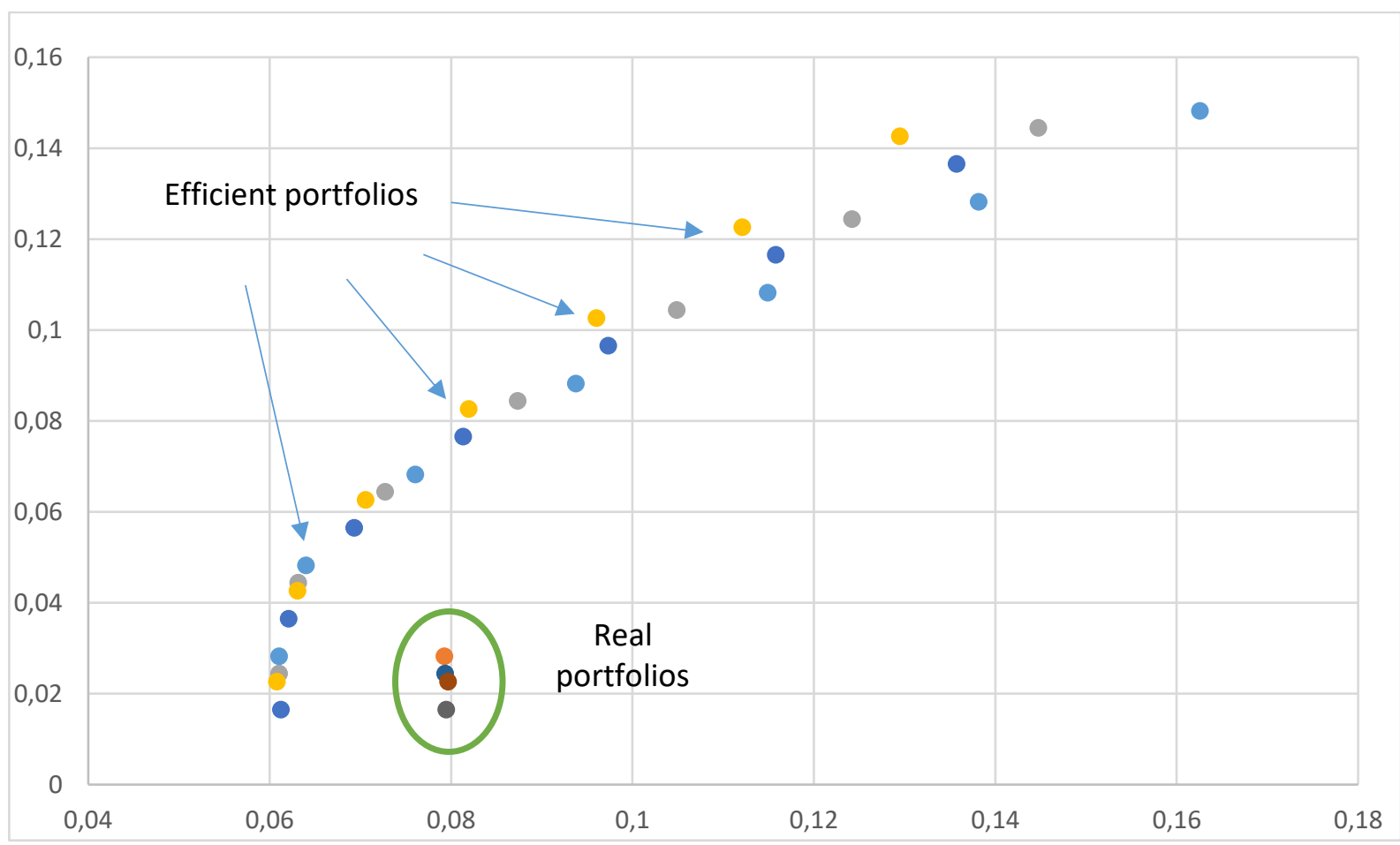

An important pitfall of the ELECTRE methods is the need for precise measurement of performance of alternatives on each criterion (the performance matrix, i.e. Table 3) and the relative role attached to each criterion, i.e. its weight. To apply the ELECTRE algorithm to our case, we must then first determine the relative importance of the criteria as well as the value of the other thresholds integrated in the ELECTRE method. Without loss of generality, we limit our illustration to three sets of weights corresponding to three decision-maker profiles (Table 4); this is part of the contribution of our paper. Decisions are taken by humans and that means that strategic decision-making frameworks need to involve the decision-maker in a decision-making process by considering her or his preferences. Following the literature (Attardi et al., 2018; Lopes et al., 2018), threshold values are calculated as a function of the maximum deviation between alternatives and by considering that q is equal to $20 \%$ of this deviation, $\mathrm{p}$ is equal to $40 \%$ of this deviation and $\mathrm{v}$ is equal to $80 \%$ of this deviation. 
Table 3: Performance matrix for the application (risk and return of efficient portfolios)

\begin{tabular}{|c|c|c|}
\hline Portfolios & Risk & Return \\
\hline 2014 P3 & $6,12 \%$ & $1,66 \%$ \\
\hline $2014 \mathrm{P} 4$ & $6,21 \%$ & $3,66 \%$ \\
\hline 2014 P5 & $6,93 \%$ & $5,66 \%$ \\
\hline 2014 P6 & $8,14 \%$ & $7,66 \%$ \\
\hline 2014 P7 & $9,73 \%$ & $9,66 \%$ \\
\hline 2014 P8 & $11,58 \%$ & $11,66 \%$ \\
\hline 2014 P9 & $13,58 \%$ & $13,66 \%$ \\
\hline $2015 \mathrm{P} 3$ & $6,08 \%$ & $2,26 \%$ \\
\hline $2015 \mathrm{P} 4$ & $6,31 \%$ & $4,26 \%$ \\
\hline 2015 P5 & $7,06 \%$ & $6,26 \%$ \\
\hline 2015 P6 & $8,19 \%$ & $8,26 \%$ \\
\hline $2015 \mathrm{P} 7$ & $9,60 \%$ & $10,26 \%$ \\
\hline 2015 P8 & $11,21 \%$ & $12,26 \%$ \\
\hline 2015 P9 & $12,95 \%$ & $14,26 \%$ \\
\hline 2016 P3 & $6,10 \%$ & $2,45 \%$ \\
\hline 2016 P4 & $6,32 \%$ & $4,45 \%$ \\
\hline 2016 P5 & $7,27 \%$ & $6,45 \%$ \\
\hline 2016 P6 & $8,74 \%$ & $8,45 \%$ \\
\hline 2016 P7 & $10,49 \%$ & $10,45 \%$ \\
\hline 2016 P8 & $12,42 \%$ & $12,45 \%$ \\
\hline 2016 P9 & $14,48 \%$ & $14,45 \%$ \\
\hline 2017 P3 & $6,10 \%$ & $2,82 \%$ \\
\hline $2017 \mathrm{P} 4$ & $6,40 \%$ & $4,82 \%$ \\
\hline 2017 P5 & $7,61 \%$ & $6,82 \%$ \\
\hline 2017 P6 & $9,38 \%$ & $8,82 \%$ \\
\hline 2017 P7 & $11,49 \%$ & $10,82 \%$ \\
\hline 2017 P8 & $13,82 \%$ & $12,82 \%$ \\
\hline 2017 P9 & $16,26 \%$ & $14,82 \%$ \\
\hline
\end{tabular}

Table 4: Sets of criteria weights and thresholds for three decision-maker profiles

\begin{tabular}{|c|c|c|}
\hline Criteria & Return & Risk \\
\hline Risk-adverse decision maker & 0.3 & 0.7 \\
\hline Neutral decision maker & 0.5 & 0.5 \\
\hline Risk-lover decision maker & 0.7 & 0.3 \\
\hline Indifference thresholds (qj) & $1.32 \%$ & $1.02 \%$ \\
\hline Preference thresholds (pj) & $2.63 \%$ & $2.04 \%$ \\
\hline Veto thresholds (vj) & $10.54 \%$ & $8.14 \%$ \\
\hline
\end{tabular}

Data have been codified using the XMCDA language and introduced in the Diviz software. The Diviz software performs computations required by MCDM methods through a simple design and quick execution of successive steps of the dedicated algorithm (the ELECTRE III one in our case). The Diviz workflow is given in the Figure 4. The workflow illustrates the ELECTRE algorithm: building outranking relations by considering two conditions (concordance and discordance) and ranking alternatives by considering two pre-orders. It 
permits tourism economics researchers to replicate our approach to other destinations.

Following Cailloux et al. (2013), we can say that the large green rounded boxes represent the calculation modules whereas the smaller blue rectangles represent various files related to the data used. The workflow is organized into 3 steps from the left to the right. Step 1 is about data which have to be codified to the XMCDA language. Step 2 concerns the ELECTRE III algorithm which is well known by MCDM experts (concordance, discordance and outranking). Step 3 is about the output of the algorithm that is the ranking of portfolios.

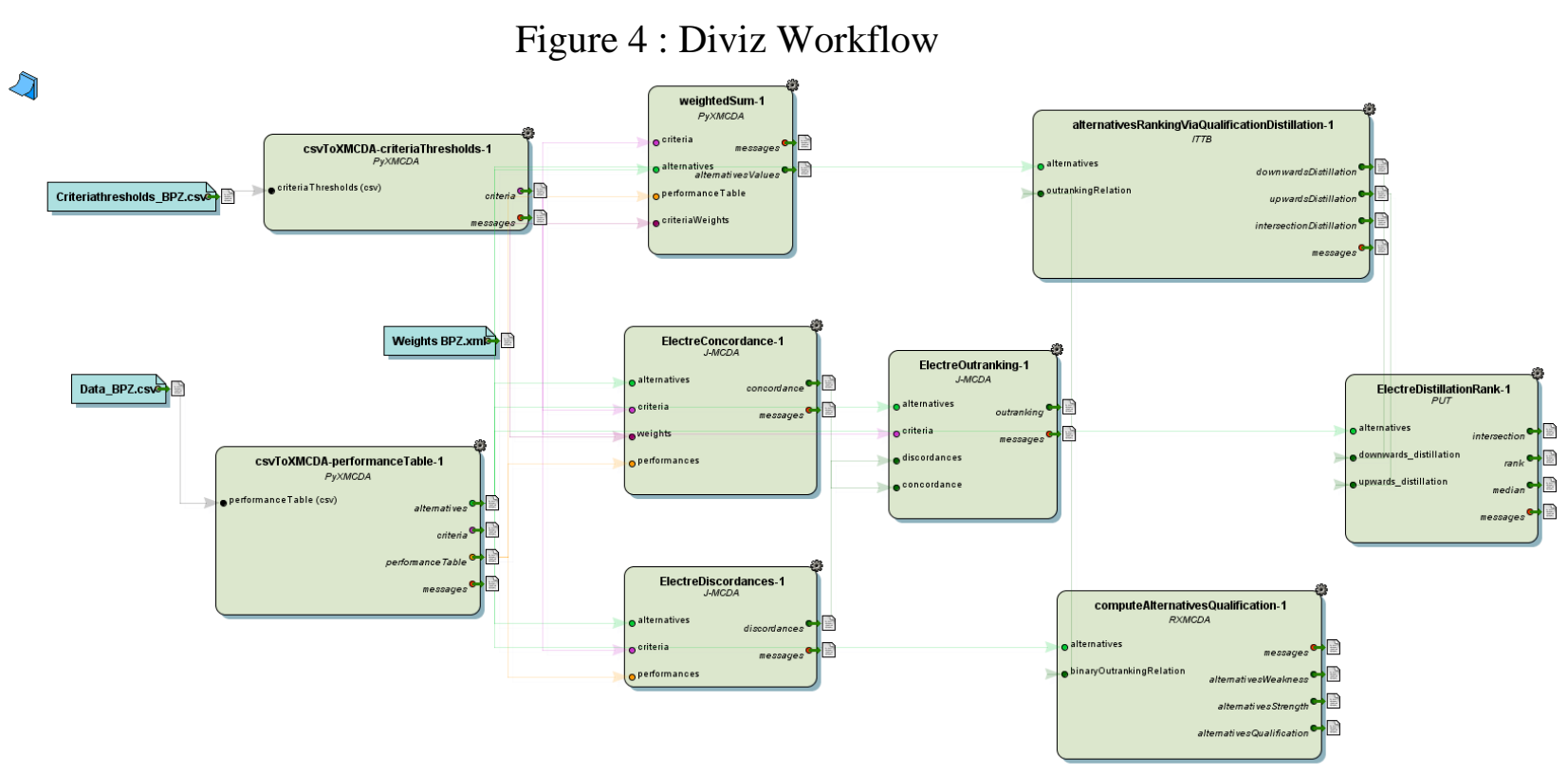

The ELECTRE III method aims at ranking alternatives from the best to the worst. To do so, it first builds outranking relations between alternatives (portfolios) and secondly constructs rankings. The ascending and descending distillation procedures lead each to a complete preorder. A final ranking is generated as the intersection of the two pre-orders. The final ranking, as illustrated in Table 5, is a partial ranking resulting from the indifference parameters given in the table 4. As an example, portfolio \#2016 P7 and portfolio \#2017 P7 are at the same rank in the risk-lover ranking (i.e. 10) as the differences between these two portfolios are below the indifference thresholds (q) $(1.00 \%$ for the difference between their respective risk and $0.38 \%$ for the difference between their respective returns). 
Table 5: Portfolios ranking for different decision-maker profiles

\begin{tabular}{|c|c|c|c|}
\hline \multirow[b]{2}{*}{ Portfolios } & \multicolumn{3}{|c|}{ Ranking for each decision maker profile } \\
\hline & Risk adverse & Neutral & Risk lover \\
\hline 2014 P3 & 16 & 26 & 24 \\
\hline 2014 P4 & 8 & 20 & 20 \\
\hline 2014 P5 & 3 & 9 & 16 \\
\hline 2014 P6 & 12 & 11 & 14 \\
\hline 2014 P7 & 18 & 13 & 11 \\
\hline $2014 \mathrm{P} 8$ & 19 & 12 & 6 \\
\hline 2014 P9 & 22 & 17 & 4 \\
\hline 2015 P3 & 13 & 24 & 23 \\
\hline $2015 \mathrm{P} 4$ & 7 & 16 & 19 \\
\hline 2015 P5 & 1 & 4 & 15 \\
\hline $2015 \mathrm{P} 6$ & 10 & 5 & 11 \\
\hline 2015 P7 & 14 & 2 & 9 \\
\hline 2015 P8 & 17 & 1 & 2 \\
\hline 2015 P9 & 15 & 3 & 1 \\
\hline 2016 P3 & 11 & 23 & 22 \\
\hline 2016 P4 & 6 & 14 & 18 \\
\hline 2016 P5 & 2 & 7 & 13 \\
\hline 2016 P6 & 14 & 8 & 12 \\
\hline 2016 P7 & 19 & 10 & 10 \\
\hline 2016 P8 & 20 & 12 & 5 \\
\hline 2016 P9 & 23 & 19 & 3 \\
\hline 2017 P3 & 9 & 22 & 21 \\
\hline $2017 \mathrm{P} 4$ & 5 & 12 & 17 \\
\hline 2017 P5 & 4 & 6 & 14 \\
\hline 2017 P6 & 17 & 15 & 12 \\
\hline 2017 P7 & 21 & 18 & 10 \\
\hline 2017 P8 & 24 & 21 & 7 \\
\hline $2017 \mathrm{P9}$ & 25 & 25 & 8 \\
\hline
\end{tabular}

This application illustrates how French Polynesia, as a destination, can reach different objectives considering its attitude towards risk. Table 6 exposes three portfolios as goals for the DMO, which must focus on the different markets depending on its objective. These goals correspond to the set of decision-maker profiles. For the first profile, the decision-maker wants to minimize risk (Return=0.3 and Risk=0.7). In the last profile, this is the opposite case and the decision-maker targets return (Return=0.7 and Risk=0.3). The neutral case concerns a profile with the same weight between risk and return. To reduce risk and stabilize demand, the DMO of French Polynesia needs to increase overnight stays of tourists from France, Europe and South America. This aim will allow the destination to dispose of a more stable tourist attendance portfolio. If the decision-maker wants to target returns (he or she is therefore a risk lover), he or she must bet on China since tourists of this origin must reach $28 \%$ of the portfolio. In fact, whatever the risk aversion profile, the Polynesian DMO has to invest clearly more on the Chinese tourists. This demand is the most promising given it is an emerging market for which overnight stays are increasing. In contrast, Japanese, Canadian and US demands are unstable given the lack of links between French Polynesia and these countries, and more precisely given the quality expectations of these tourists. Further, as indicated by 
Poirine (2011), French Polynesia had chosen a luxury tourist product named 'overwater bungalow', which was also adopted by other destinations like the Maldives and Seychelles consecutively but with lower tariffs. This could explain the volatility of the demand from these markets. Accordingly, in terms of managerial recommendations, our framework is useful, permitting the DMO to build strategies concerning attendance, length of stay and promotions focused on different inbound markets.

Moreover, the result concerning Chinese tourists makes sense for the French Polynesia DMO. For the Asian market, there are only two possibilities concerning air connectivity: from Auckland or from Tokyo. The second line presents difficulties for the local company Air Tahiti Nui (the occupancy rate was close to $70 \%$ on average in 2017). Since the local DMO keep willing to attract Japanese tourists, Air Tahiti Nui currently continue to exploit this line despite booking difficulties. However, the question to attract the Asian tourists via another connection (to Hong-Kong?) is asked by the local experts. The argument to maintain the line Tokyo-Papeete (and to avoid the development of a line to a Chinese city) is the following: the tourism demand from China is unstable. Our results demonstrate clearly, whatever the risk aversion of the decision maker, that this argument is wrong.

Table 6: Real portfolio in 2017 and optimal portfolios for different decision-maker profiles

\begin{tabular}{|c|c|c|c|c|}
\hline & $\begin{array}{c}\text { Real portfolio in } \\
2017\end{array}$ & $\begin{array}{c}\text { Risk adverse } \\
\text { decision-maker }\end{array}$ & $\begin{array}{c}\text { Neutral } \\
\text { decision-maker }\end{array}$ & $\begin{array}{c}\text { Risk lover } \\
\text { decision-maker }\end{array}$ \\
\hline Africa & $0.21 \%$ & $0.13 \%$ & $0.13 \%$ & $0.13 \%$ \\
\hline Central America & $0.38 \%$ & $0.30 \%$ & $0.30 \%$ & $0.30 \%$ \\
\hline North America & $28.77 \%$ & $15.42 \%$ & $15.42 \%$ & $15.42 \%$ \\
\hline South America & $3.72 \%$ & $7.47 \%$ & $2.49 \%$ & $2.49 \%$ \\
\hline China & $2.63 \%$ & $11.14 \%$ & $23.95 \%$ & $28.32 \%$ \\
\hline Japan & $4.81 \%$ & $3.85 \%$ & $3.85 \%$ & $3.85 \%$ \\
\hline Europe & $4.81 \%$ & $12.27 \%$ & $12.27 \%$ & $12.27 \%$ \\
\hline France & $33.69 \%$ & $42.99 \%$ & $35.16 \%$ & $30.80 \%$ \\
\hline Total Pacific & $10.16 \%$ & $6.33 \%$ & $6.33 \%$ & $6.33 \%$ \\
\hline Middle East & $0.28 \%$ & $0.09 \%$ & $0.09 \%$ & $0.09 \%$ \\
\hline
\end{tabular}

\section{Conclusion, limits and perspectives}

DMOs face complex decision-making problems in many diverse fields, all the more when these decisions involve large amounts of money. Accordingly, decision-making requires the development of adapted methodologies to help the decision-maker. This paper proposes a decision-making process to help DMOs choose the optimal tourist origins portfolio for their respective destination. The proposed framework illustrates for DMOs what they must do, that is, it provides guidance on strategic goals for their destination. This framework is composed of two steps, and accordingly, it follows and deepens the concerned literature. Several authors have used the portfolio analysis model in tourism. This offers to the decision-maker a large set of possibilities. As a consequence, and according to the existing literature on the topic, it is nowadays a choice problem. Our paper opens a new pathway by considering the application of the MCDM ELECTRE method to assist the decision-maker in choosing an alternative (between the optimal ones). This gives the decision-maker the flexibility of choosing the relative importance of the criteria during the decision-making process. This paper has thus shown the contribution of ELECTRE to the dedicated literature on tourist origins portfolios. 
The MCDM ELECTRE method seems to have a promising future in the field. This paper focuses on ELECTRE III to propose a ranking of optimal portfolios, but alternative methods may be employed, as ELECTRE I, permitting to obtain the choice of one portfolio. However, certain limits remain and expose perspectives for further research. First, one of the advantages of our framework is that the direct intervention of the decision-maker in the decision-making process (to determine the relative importance of the criteria and the various thresholds proposed by the concept of the pseudo-criterion) provides her or him with all the necessary supports to defend the taken decision. This is also a drawback of the MCDM methods in that they rely on subjective inputs from the decision-maker. This represents one possible extension of our research in particular by considering the existing tools permitting the use of fuzzy numbers to determine the weight of criteria.

Second, a limit of our approach concerns the fundamental principle of MPT: the return of assets (tourist origins) is normally distributed. Higher moments (skewness for example) can then be ignored. In this paper, returns are not normally distributed considering that an extension of it should then comprise the consideration of skewness as proposed by Andriamasy and Rakotondramaro (2016).

After all, the mean and the variance do not incorporate all decision-maker considerations. Important aspects that affect the performance of different portfolios cannot be taken into account explicitly by return and risk. MCDM offers a logic in which both quantitative and qualitative criteria should be taken into consideration for the decision. Accordingly, an extension of this paper should be to incorporate other criteria that the decision-maker would like to use in her-his decision-making.

\section{References:}

Andrades-Caldito, L., Sanchez-Rivero, M., \& Pulido-Fernandez, J. I. (2013). Differentiating competitiveness through tourism image assessment: An application to Andalusia (Spain). Journal of Travel Research, 52(1), 68-81.

Andriamasy, L., \& Rakotondramaro, H. (2016). Mean-variance-skewness in destination efficiency framework: The case of France. European Journal of Tourism Research, 14, 92100.

Assaf, A. G. (2012). Benchmarking the Asia Pacific tourism industry: A Bayesian combination of DEA and stochastic frontier. Tourism Management, 33(5), 1122-1127.

Assaf, A. G., \& Josiassen, A. (2012). Identifying and ranking the determinants of tourism performance: a global investigation. Journal of Travel Research, 51(4), 388-399.

Assaf, A. G., \& Tsionas, M. (2015). Incorporating destination quality into the measurement of tourism performance: A Bayesian approach. Tourism Management, 49, 58-71.

Assaf, A. G., \& Tsionas, M. (2018). Measuring hotel performance: Toward more rigorous evidence in both scope and methods. Tourism Management, 69, 69-87.

Attardi, R., Cerreta, M., Sannicandro, V. \& Torre, C. M. (2018). Non-compensatory composite indicators for the evaluation of urban planning policy: The Land-Use Policy Efficiency Index (LUPEI). European Journal of Operational Research, 264, 491-507.

Barros, C.P., Botti, L., Peypoch, N., Robinot, E., Solonandrasana, B. \& Assaf, A.G. (2011). Performance of French destinations: Tourism attraction perspectives. Tourism Management, 32(1), 141-146. 
Bodie, Z., Kane, A. \& Marcus, A. J. (2009). Investments, $8^{\text {th }}$ ed, Irwin, New-York: McGraw Hill.

Botti, L., Goncalves, O., \& Ratsimbanierana. H. (2012). French Destination Efficiency: A Mean-Variance Approach. Journal of Travel Research, 51(2), 115-129.

Botti, L. \& Peypoch, N. (2013). Multi-criteria ELECTRE method and destination competitiveness. Tourism Management Perspectives, 6, 108 - 113.

Cailloux, O., Mayag, B., Meyer, P. \& Mousseau, V. (2013). Operational tools to build a multicriteria territorial risk scale with multiple stakeholders. Reliability Engineering and System Safety, 120, 88-97.

Chang, Y-T., Lee, S. \& Park, H. (2017). Efficiency analysis of major cruise lines. Tourism Management, 58, 78-88.

Corne, A. (2015). Benchmarking and tourism efficiency in France. Tourism Management, 51, 91-95.

Dropsy, V., Montet, C. and B. Poirine (2018), “Tourism, Insularity and Remoteness: a Gravity-Based Approach", QATEM Workshop, University of French Polynesia, $15^{\text {th }}$ June 2018.

Figueira, J., Mousseau, V., \& Roy, B. (2005). ELECTRE methods. In Figueira, J., Greco, S., \& Ehrgott, M., editors, Multiple Criteria Decision Analysis: State of the Art Surveys, pages 133-162. Springer Verlag, Boston, Dordrecht, London.

Giannoulis, C., \& Ishizaka, A. (2010). A Web-based decision support system with ELECTRE III for a personalized ranking of British universities. Decision Support Systems, 48(3), 488497.

Goncalves, O. (2013). Efficiency and productivity of French ski resorts. Tourism Management, 36, 650-657.

Hatami-Marbini, A., \& Tavana, M. (2011). An extension of the Electre I method for group decision-making under a fuzzy environment. Omega, 39, 373-386.

Ishizaka, A., Nemery, P., \& Lidouh, K. (2013). Location selection for the construction of a casino in the Greater London region: A triple multi-criteria approach. Tourism Management, 34, 211-220.

Jang, S. (2004). Mitigating tourism seasonality: A quantitative approach. Annals of Tourism Research, 31(4), 819-836.

Jang, S., \& Chen, M. H. (2008). Financial portfolio approach to optimal tourist market mixes. Tourism Management, 29(4), 761-769.

Kennedy, V. (1998). Risk management in the Irish tourism industry: The contribution of a portfolio investment approach. Tourism Management, 19(2), 119-126.

Lopes, A. P., Munoz, M., \& Alarcon-Urbistondo, P. (2018). Regional tourism competitiveness using the Promethee approach. Annals of Tourism Research, 73, 1-13.

Markowitz, H. (1952). Portfolio Selection. Journal of Finance, 7, 77-91.

Papadopoulos, A., \& Karagiannidis. A. (2008). Application of the multi-criteria analysis method ELECTRE III for the optimization of decentralised energy systems. Omega, 36(5), 766-776. 
Petit, S. (2018), « Une nouvelle compagnie aérienne internationale en Polynésie française : et après ? », Pacific Islands Universities Research Network Confrence, 2018, Université de la Polynésie française, 8-10th October 2018, hal-02138654, https://hal.archives-ouvertes.fr/hal$02138654 \mathrm{v} 1$

Poirine, B. (2011), Tahiti : une économie sous serre, L'Harmattan: Paris.

Rakotondramaro, H., \& Botti, L. (2018). Optimizing tourist demands with utility efficient frontier. Tourism Economics, 24(2), 157-166.

Ratsimbanierana, H., Sbai, S. \& Stenger, A. (2013). Moroccan tourist portfolio efficiency with the mean-variance approach. European Journal of Tourism Research, 6(2), 122-131.

Rogers, M., Bruen, M., \& Maystre, L. Y. (2000). ELECTRE and decision support. Dordrecht: Kluwer Academic Publishers.

Roy, B. (1991). The outranking approach and the foundations of ELECTRE methods. Theory and Decision, 31, 49-73.

Sainaghi, R. (2006). From contents to processes: Versus a dynamic destination management model (DDMM). Tourism Management, 27, 1053-1063.

Seraphin, H., Ambaye, M., Gowreesunkar, V., \& Bonnardel, V. (2016). A marketing research tool for destination marketing organizations' logo design. Journal of Business Research, 69, 5022-5027.

Sinclair, M. (1999). Economic and Management Methods for Tourism and Hospitality Research, Chapter Portfolio Models of Tourism, 25-37. Wiley, Chichester, T. Baum and R. Mudambi edition.

Stauvermann, P. J., \& Kumar, R. R. (2016). Economics of tourism \& growth for small island countries. Tourism Management, 55, 272-275.

Zhang, L., Botti, L., \& Petit, S. (2016). Destination performance: Introducing the utility function in the mean-variance space, Tourism Management, 52,123-132.

Zopounidis, C. (1999), Multicriteria decision aid in financial management. European Journal of Operational Research, 119, 404-415. 